TP Periodica Polytechnica

Transportation Engineering

47(2), pp. 91-95, 2019

https://doi.org/10.3311/PPtr. 11560

Creative Commons Attribution (i)

\section{Fracture Toughness Evaluation of S355 Steel Using Circumferentially Notched Round Bars}

\author{
Fatih Bozkurt $^{1 *}$, Eva Schmidová ${ }^{1}$
}

Received 12 March 2017; accepted 05 October 2017

\begin{abstract}
In engineering applications, steels are commonly used in various areas. The mechanical members are exposed to different loading conditions and this subject can be investigated in fracture mechanics. Fracture toughness $\left(K_{I C}\right)$ is the important material property for fracture mechanics. Determination of this properties is possible using a compact tension specimen, a single edge notched bend or three-point loaded bend specimen, which are standardized by different institutions. Researchers underline that these standardized methods are complex, the manufacturing process is difficult, they require special fixtures for loading during the experiment and the test procedures are time consuming. Alternative methods are always being sought by researchers. In this work, two different approaches are investigated for S355 steels. In the first method, a circumferentially cracked round bar was loaded in tensile mode and pulled till failure. Using suitable equations, fracture toughness can be calculated. In the second method, a circumferentially notched bar specimen without fatigue pre-cracking was loaded in a tensile machine. By means of fracture load values, fracture toughness was determined by the proposed equations. It can be stated that these two different approaches for calculating fracture toughness are simple, fast and economical.
\end{abstract}

\section{Keywords}

fracture toughness, notched round bars, pre-cracked specimen

This article was originally published with an error. This version has been corrected/amended. Please see Corrigendum (https://doi.org/10.3311/PPtr.12579)

\footnotetext{
${ }^{1}$ Department of Mechanics, Materials and Machine Parts, Jan Perner Transport Faculty, University of Pardubice, Pardubice, Studentská 95, Czech Republic

*Corresponding author, e-mail: st43852@student.upce.cz
}

\section{Introduction}

Fracture is a problem that society has faced for as long as the man - made structures existed. Fracture mechanics is the branch of solid mechanics. This branch explains behaviour of bodies having cracks under different loading conditions. The reasons of most structural failures are negligence during design, construction of the structure, application of new design or material which produces an unexpected result. If the structural member contains a crack, then the component becomes weak and finally fracture occurs. Fracture toughness is the measure of resistance to crack propagation. Machines and structural, components are oversized in order to avoid failure. This situation leads to the consumption of more material than designed and thus a high price. The main reason for these problems is the non-availability of fracture toughness data. In this respect, the value of fracture toughness is useful in designing machine or structural components which are strong but not oversized and overly heavy.

Fracture toughness is measured in terms of $\mathrm{K}_{\mathrm{IC}}$ (plane strain fracture toughness), where $\mathrm{K}$ stands for the stress intensity factor at the crack tip, "I" denotes the fracture toughness test is performed in tensile mode and " $\mathrm{C}$ " denotes that value $\mathrm{K}$ is critical. When $\mathrm{K}$ attains a critical value crack propagation then becomes unstable and results in fracture of the components (Dieter, 1988). Generally, $\mathrm{K}_{\mathrm{IC}}$ is determined by different methods such as using a compact tension specimen, a single edge notched bend or three-point loaded bend specimens. Some institutions have proposed several fracture toughness measurement methods, for example, the American Society for Testing and Materials (ASTM Designation). But the proposed methods are difficult and also time consuming. Fast and reliable test methods are always being sought by researchers. In the literature, there are two different approaches to determining fracture toughness of metallic materials. The first approach uses a notched round bar that is allowed to rotate under fatigue load in an R.R. Moore fatigue testing machine, then a pre-cracked specimen is loaded in a tensile testing machine and pulled till failure. After that, crack lengths are measured with optical measuring devices and fracture toughness calculated using the 
proposed equations (Londe et al., 2010; Londe et al., 2015). The second approach uses a notched round bar that is directly loaded in a tensile testing machine, and fracture toughness is calculated using suitable equations (Bayram et al., 2002;Bayram and Uguz, 1999; Bayram et al., 1999; Alaneme, 2011) and the advantages of using circumferentially notched bars for fracture toughness testing can be summarized as follows:

- The plane strain condition can be obtained;

- Because of radial symmetry of heat transfer, the microstructure of material along the circumferential area is completely uniform;

- Machining and preparation of the specimens are easy;

- Performing of the fracture toughness test is simple;

- Does not require any special fixtures to mount to specimen and costly instrumentation like clip gauge (Bayram et al., 2002 and Londe et al., 2015)

In this work, two different approaches were examined for S355 steels and the results between the two methods were compared.

\section{Experimental Procedure}

S355 steels are structural steels that are used extensively in general engineering applications. They are particularly useful because they offer a unique combination of good welding properties with guaranteed strengths. The chemical composition of the steel used for the tests is shown in Table 1. No heat treatment was applied.

Table 1 Chemcial Composition of S355 (wt. \%)

\begin{tabular}{lllll}
\hline $\mathrm{C}$ & $\mathrm{Mn}$ & $\mathrm{Si}$ & $\mathrm{P}$ & $\mathrm{S}$ \\
\hline 0.2 & 1.82 & 0.27 & 0.012 & 0.003 \\
\hline
\end{tabular}

Microstructure of S355 steel is shown in Fig. 1. It consists equiaxed grains ferrite - pearlite microstructure. Lines shaped micro volumes of pearlite is observed as a primary heterogeneity of carbon content.

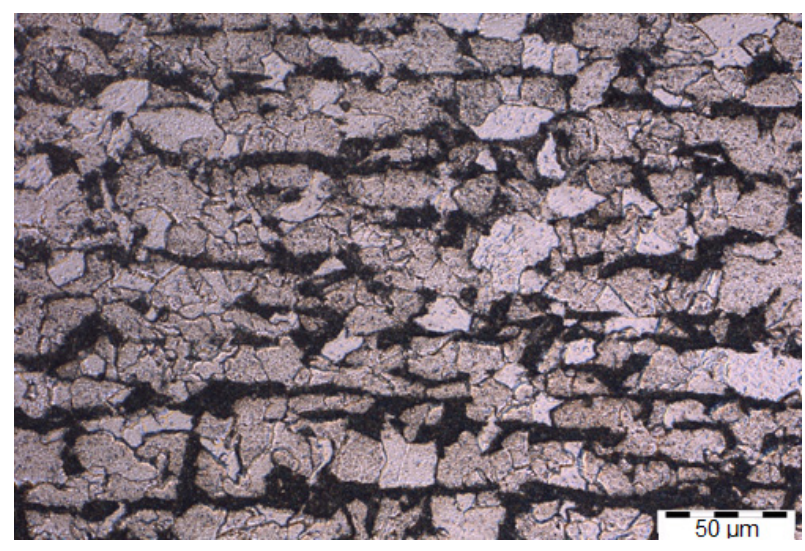

Fig. 1 Microstructure of S355 steel
The round bar specimens were machined for the fatigue and tensile tests. The dimensions of the specimens were: gauge length $220 \mathrm{~mm}\left(\mathrm{~L}_{0}\right)$, diameter of notched section $10 \mathrm{~mm}(\mathrm{~d})$, diameter of unnotched section $12 \mathrm{~mm}(\mathrm{D}), \mathrm{V}$-notch angle $(\alpha)$ $60^{\circ}$ as shown in Fig. 2.

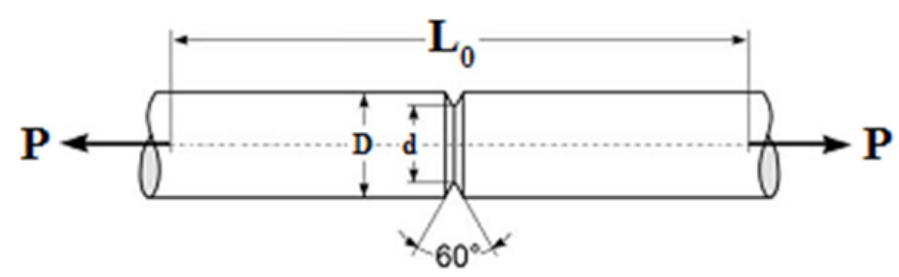

Fig. 2 Dimensions of round bar specimens

For the pre-cracking procedure, the samples were subjected to cyclic tensile - compressive loads of equal amplitude were applied with the stress ratio $\mathrm{R}$ equal to minus one $(\mathrm{R}=-1)$. Pre-cracking (shown in Fig. 3) was done at a suitable bending load (M) using a four-point R.R. Moore rotating beam fatigue testing machine (shown in Fig. 4).

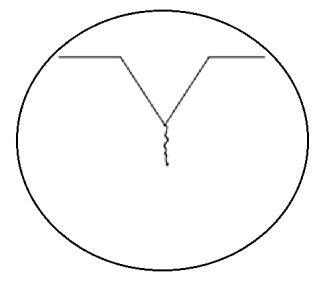

Fig. 3 Fatigue crack at notch tip

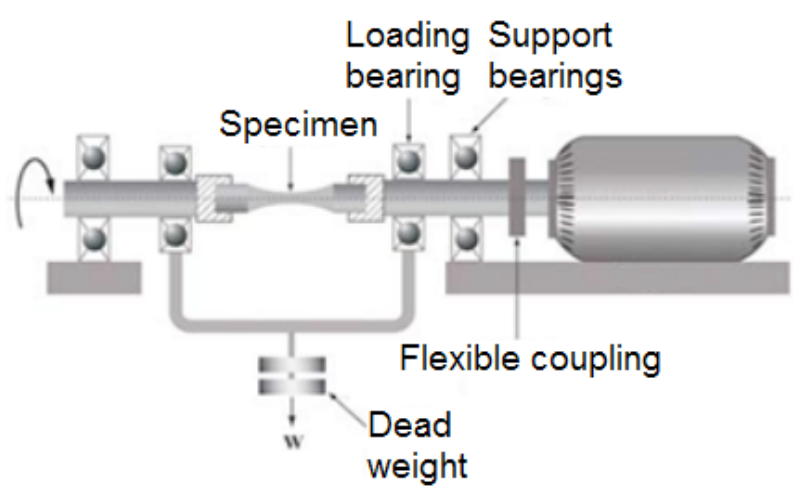

Fig. 4 R.R. Moore rotating beam fatigue testing machine

The limit load selected was such that the maximum stress intensity factor $\left(\mathrm{K}_{\max }\right)$ should not exceed $60 \%$ of the minimum expected fracture toughness $\mathrm{K}_{\mathrm{IC}}$ of the test material. In the present work, a $40 \mathrm{~kg}$ mass was hung from the fatigue testing machine. Three samples were subjected to the fatigue tests with a differing number of cycles and then pre-cracked samples were loaded monotically in tension with a crosshead displacement rate of $0.5 \mathrm{~mm} / \mathrm{min}$ until failure. The displacement was measured using extensometer (Fig. 5). 


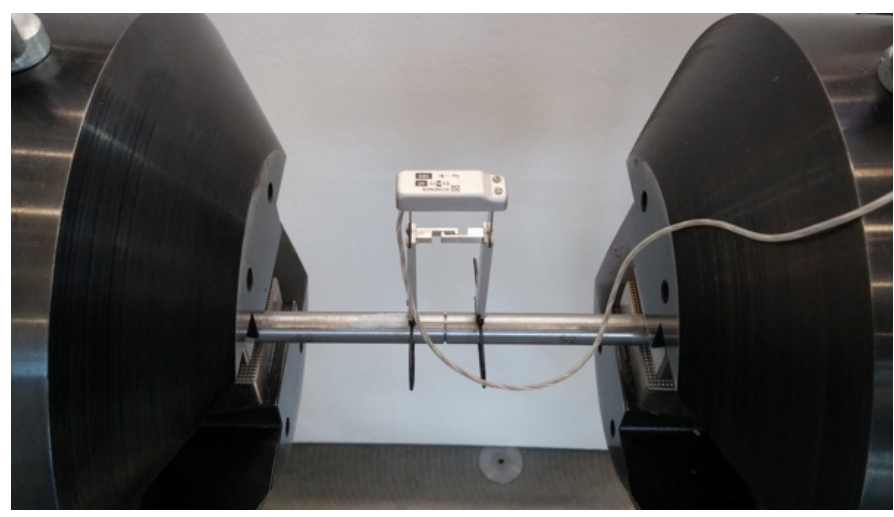

Fig. 5 Mounted round bar specimen and extensometer

For calculation of the fracture toughness value, crack lengths of the fractured surface were examined by scanning electron microscopy (SEM). The effective diameter $\left(d_{\text {eff }}\right)$ was calculated by the sum of the machined notch depth $\left(a_{m}\right)$ and the length of the fatigue pre-crack $\left(a_{f}\right)$ as in Eq. (1)

$$
d_{\text {eff }}=D-2\left(a_{m}+a_{f}\right)
$$

Equation (1) is used for calculation of the fracture toughness in Eq. (2) (Londe et al., 2015) where $P_{f}$ is the fracture load,

$$
K_{I C}=\frac{P_{f}}{D^{3 / 2}} \times\left[1.72\left(\frac{D}{d_{\text {eff }}}\right)-1.27\right]
$$

The valid range for the use of Eq. (2) is $0.46<d_{e f f} / D<0.86$, where $d_{\text {eff }}$ is the effective ligament diameter.

The second approach uses a notched round bar without fatigue test that is directly loaded in a universal tension testing machine. The term of the notched tensile strength $\left(\sigma_{N T S}\right)$ is calculated by Eq. (3) where $P_{f}$ is the fracture load

$$
\sigma_{N T S}=\frac{4 \times P_{f}}{\pi \times d^{2}}
$$

Eq. (3) is used for calculation of the fracture toughness in Eq. (4) (Bayram et al., 2002) where $P_{f}$ is the fracture load,

$$
K_{I C}=0.454 \times \sigma_{N T S} \times D^{1 / 2}
$$

Some researchers suggest using Eq. (5), which is same as Eq. (2) (Dieter, 1998), but in this formula the notched section diameter is used instead of $\left(d_{e f f}\right)$ for calculation of the fracture toughness,

$$
K_{I C}=\frac{P_{f}}{D^{3 / 2}} \times\left[1.72\left(\frac{D}{d}\right)-1.27\right]
$$

\section{Results}

During the experiments, an electro-hydraulic test stand was used for tensile testing in both approaches (Fig. 6).

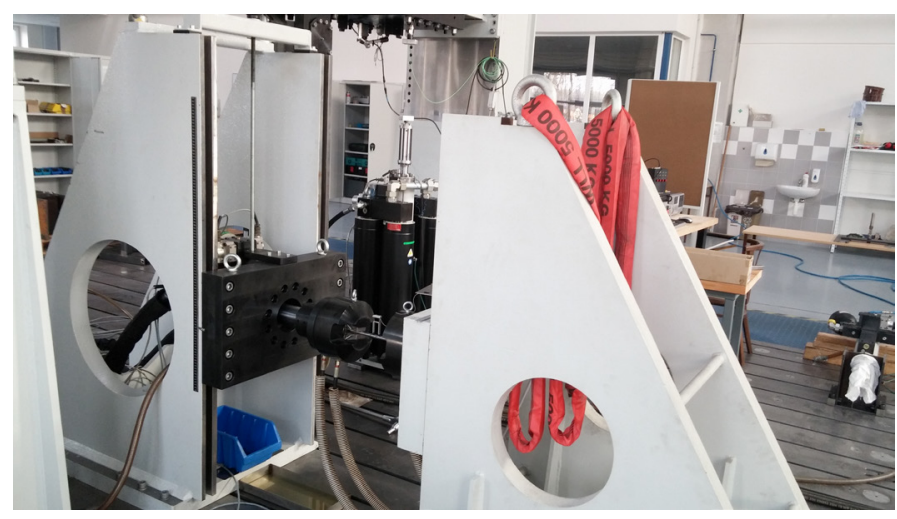

Fig. 6 Electro - hydraulic test stand

Fracture load which is maximum force can be read from data acquisition for every specimen. The representative force - displacement graph of the tensile test is shown in Fig 7. The most important parameters for this approach are the dimensions of fractured surface of specimen after tensile test. The samples are cut and prepared for scanning electron microscopy. The machined notch depth $\left(\mathrm{a}_{\mathrm{m}}\right)$ and the length of the fatigue pre-crack $\left(\mathrm{a}_{\mathrm{f}}\right)$ are measured circumferential direction of fractured surface (Fig. 8). At least 4 points are measured and average values are calculated. The fracture toughness values calculated using Eq. (2) from the data of the tensile test on the circumferentially cracked round bar (CCRB) specimens and also the dimensions of the fractured surface (with SEM observations), fracture load, notched and unnotched dimension, are tabulated in Table 2.

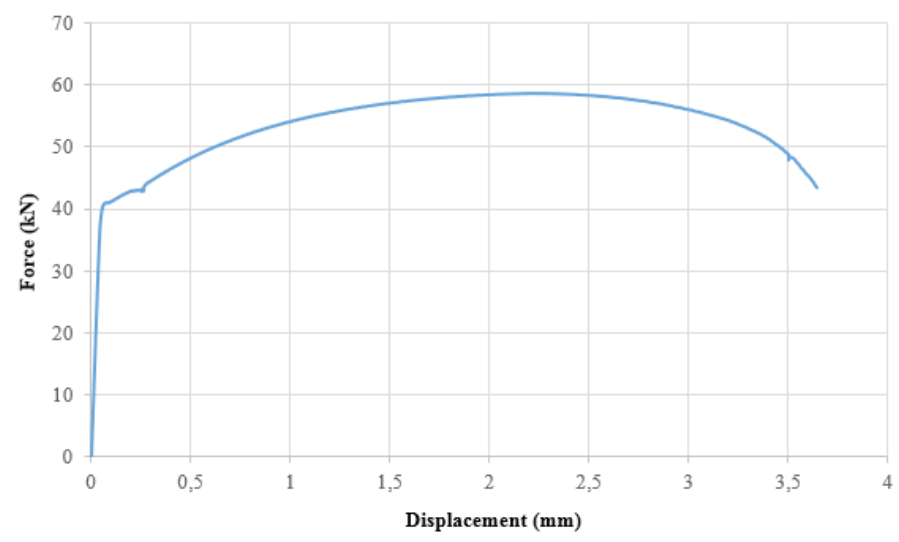

Fig. 7 Representative force - displacement graph of the tensile test

Table 2 Summary of Fracture Toughness Values and Dimensions for CCRB specimen

\begin{tabular}{llllllll}
\hline $\begin{array}{l}\text { Sample } \\
\text { No }\end{array}$ & $\mathrm{P}_{\mathrm{f}} \mathrm{kN}$ & $\begin{array}{l}\mathrm{D} \\
\mathrm{mm}\end{array}$ & $\mathrm{a}_{\mathrm{m}} \mathrm{mm}$ & $\mathrm{a}_{\mathrm{f}} \mathrm{mm}$ & $\begin{array}{l}\mathrm{d}_{\text {eff }} \\
\mathrm{mm}\end{array}$ & $\mathrm{d}_{\text {eff }} / \mathrm{D}$ & $\begin{array}{l}\mathrm{K}_{\mathrm{IC}} \\
\mathrm{MPa} \sqrt{m}\end{array}$ \\
\hline $\mathrm{S}-1$ & 46.6 & 11.9 & 0.99 & 0.67 & 8.58 & 0.72 & 40.4 \\
$\mathrm{~S}-2$ & 47.6 & 11.8 & 0.98 & 0.5 & 8.84 & 0.74 & 38.13 \\
$\mathrm{~S}-3$ & 51.4 & 11.72 & 0.99 & 0.188 & 9.36 & 0.79 & 35.78 \\
\hline
\end{tabular}




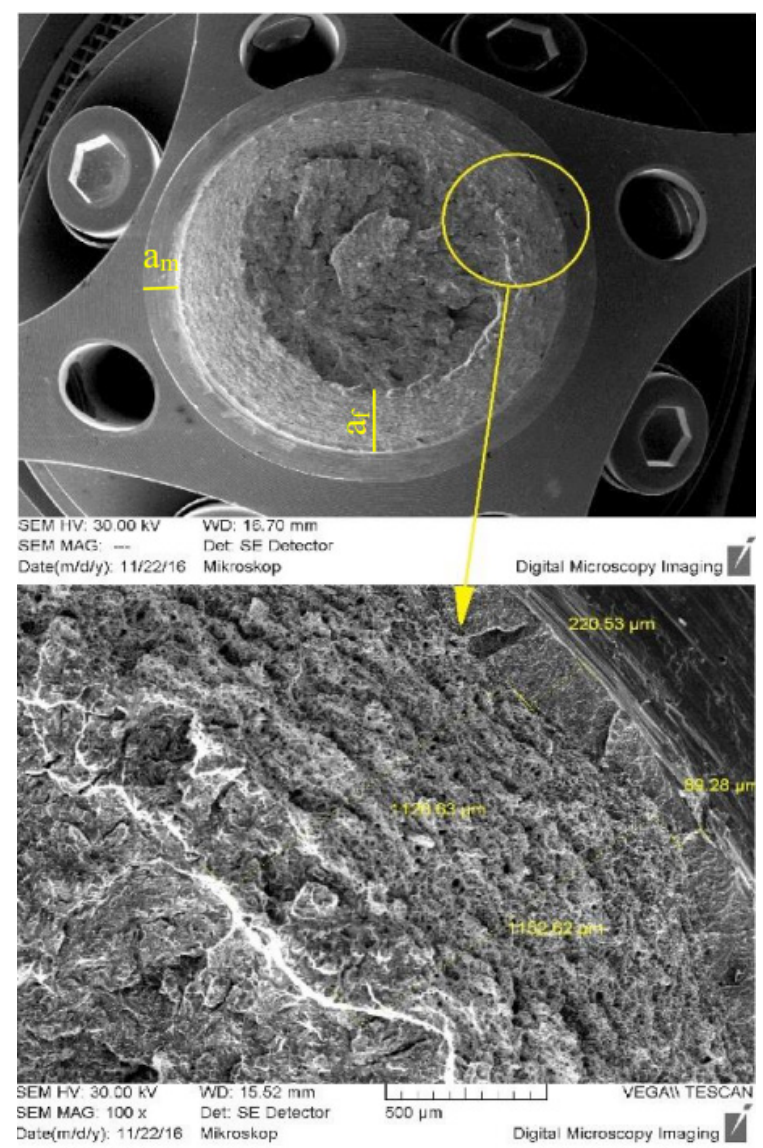

Fig. 8 Representative force - displacement graph of the tensile

The fracture toughness $\left(\mathrm{K}_{\mathrm{IC}}\right)$ of S355 steel varies from 35.78 $\mathrm{MPa} \sqrt{m}$ to $40.4 \mathrm{MPa} \sqrt{m}$. The average fracture toughness experimentally obtained is $38.1 \mathrm{MPa} \sqrt{m}$.

According to the second approach, which uses notched bar specimens without fatigue pre-cracking, the calculated fracture toughness $\left(\mathrm{K}_{\mathrm{IC}}\right)$ varies from $39.4 \mathrm{MPa} \sqrt{m}$ to $39.9 \mathrm{MPa} \sqrt{m}$ and the average value is $39.6 \mathrm{MPa} \sqrt{m}$ for Eq. (4). Because the fracture toughness values were calculated by using the fracture loads of the notched specimens, an increase in fracture toughness with the increase in notch tensile strength is evident. Fracture toughness was also calculated using Eq. (5) and in this approach the values vary from $37.78 \mathrm{MPa} \sqrt{m}$ to 38.20 $\mathrm{MPa} \sqrt{m}$ and the average value is $37.94 \mathrm{MPa} \sqrt{m}$. Fracture toughness, notch tensile strength and also dimension are tabulated in Table 3. According to the results without precracked methodology, the calculated fracture toughness values using Eq. (4) and Eq. (5) are in good agreement.

Table 3 Summary of Fracture Toughness Values and Dimensions for Notched Bar Specimens

\begin{tabular}{lllllll}
\hline $\begin{array}{l}\text { Sample } \\
\text { No }\end{array}$ & $\mathrm{P}_{\mathrm{f}} \mathrm{kN}$ & $\mathrm{D} \mathrm{mm}$ & $\mathrm{d} \mathrm{mm}$ & $\begin{array}{l}\sigma_{N T S} \\
\mathrm{MPa}\end{array}$ & $\begin{array}{l}\mathrm{K}_{\mathrm{IC}} \\
\mathrm{MPa} \sqrt{m} \\
\text { Eq. (4) }\end{array}$ & $\begin{array}{l}\mathrm{K}_{\mathrm{IC}} \\
\mathrm{MPa} \sqrt{m} \\
\text { Eq. (5) }\end{array}$ \\
\hline S-4 & 58.19 & 11.58 & 9.58 & 807.3 & 39.4 & 37.78 \\
S-5 & 59.88 & 11.68 & 9.68 & 813.7 & 39.9 & 38.20 \\
S-6 & 58.71 & 11.62 & 9.62 & 807.7 & 39.5 & 37.85 \\
\hline
\end{tabular}

The fracture surfaces of un-precracked S355 sample is shown in Fig. 9 in loading direction and perpendicular to the loading direction (side view of the samples). The surface of S355 steel has moderate amount of necking and it is almost cup and cone fracture characteristics. In central region has an irregular and fibrous appearance, which signifies plastic deformation. In outer side of the fracture surface can be seen $45^{\circ}$ shear lips. This angle represents the direction of maximum shear stress that causes shear lip in final stage.

The value of the fracture toughness difference between Eq. (2) and Eq. (4) is about 3\% and the difference between Eq. (2) and Eq. (5) is about 4\%. It can be stated that the results of the method which uses notched bar specimens are more consistent than the first method. In the literature, the fracture toughness of structural steels (including low, medium and high carbon steels) varies from $12 \mathrm{MPa} \sqrt{m}$ to $92 \mathrm{MPa} \sqrt{m}$ . These values are calculated using standardized test methods while some of them also concern heat treated steels, which means that higher fracture toughness values can be achieved (Materials Data Book, 2003).
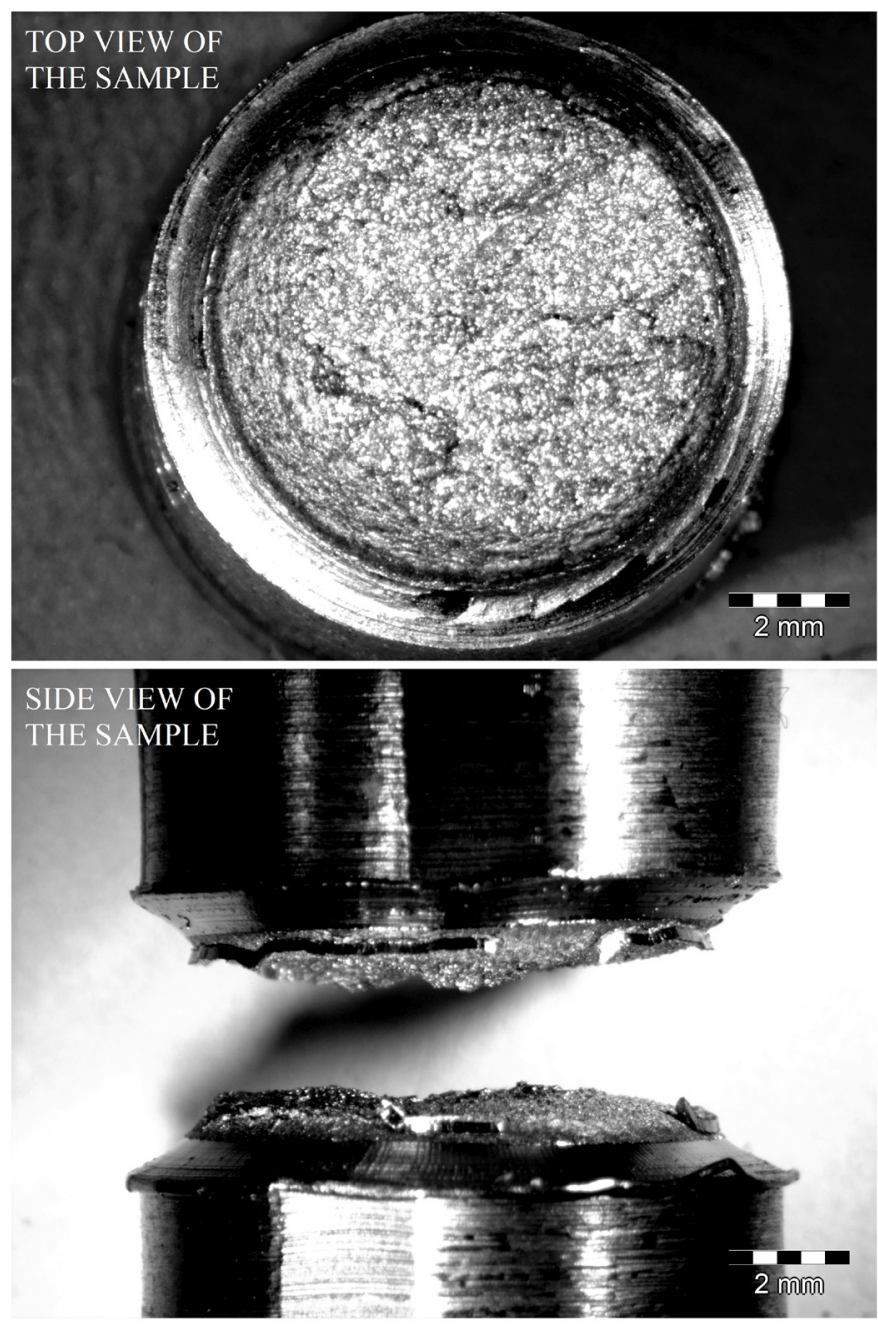

Fig. 9 The fractured surface of un - precracked of the sample 


\section{Conclusions}

In this research, a method which uses a circumferentially cracked round bar (CCRB) specimen and another approach which uses a circumferentially notched bar specimen not fatigue pre-cracked, can be used to determine the fracture toughness values of metallic materials and they are observed to be reliable procedure. The difference between two different suggested approaches is remarkable and it is investigated from fracture mechanics aspect. The SEM and optical observations of tensile fractured surface shows two different regions which are pre-cracked regions and sudden crack growth regions. The fatigue fractured surfaces smoother than the tensile fractured surfaces. The methodology of these experiments is simple, and saves time regarding specimen preparation and the test procedures. They use simple instrumentation and do not require costly measuring devices and equipment. The obtained values are found to be in good agreement with the literature but in future experiments standardized test methods should be performed on samples of S355 steel, the methods could be compared and the suggested equations should also be investigated.

\section{Acknowledgement}

This work was made possible with the support of the student grant system of the University of Pardubice, project number SGS_2017_009.

\section{References}

Alaneme, K. K. (2011). Fracture Toughness $\left(\mathrm{K}_{\mathrm{IC}}\right)$ Evaluation for Dual-Phase Medium-Carbon Low-Alloy Steels Using Circumferential Notched Tensile (CNT) Specimens. Materials Research. 14(2), pp. 155-160. https://doi.org/10.1590/S1516-14392011005000028

ASTM Designation E399-12e3 (2012). Standard Test Method for Linear-Elastic Plane-Strain Fracture Toughness $\mathrm{K}_{\mathrm{IC}}$ of Metallic Materials. https://doi.org/10.1520/E0399

Bayram, A., Uguz, A. (1999). The Effect of a Notch on the Tensile Properties of a Commercial 7075-Al Alloy. Metal. 53(9), pp. 486-489.

Bayram, A., Uguz, A., Ula, M. (1999). Effect of Microstructure and Notches on the Mechanical Properties of Dual-Phase Steels. Materials Characterization. 43, pp. 259-269.

https://doi.org/10.1016/S1044-5803(99)00044-3

Bayram, A., Uguz, A., Durmus, A. (2002). Rapid Determination of the Fracture Toughness of Metallic Materials Using Circumferentially Notched Bars. Journal of Materials Engineering and Performance. 11, pp. 571-576. https://doi.org/10.1361/105994902770343836

Dieter, G. E. (1988). Chapter 11. In: Mechanical Metallurgy. (pp. 348-374), SI ed., McGraw-Hill, Singapore

Londe, V. N., Jayaraju, T., Sadananda, P. R. (2010). Use of Round Bar Specimen in Fracture Toughness Test of Metallic Materials. International Journal of Engineering Science and Technology. 2(9), pp. 4130-4136.

Londe, V. N., Jayaraju, T., Sadananda, P.R., Padmayya N., Kumar D., Mohankumar (2015). Determination of Fracture Toughness and Fatigue Crack Growth Rate Using Circumferentially Cracked Round Bar Specimens of A12014T651. Aerospace Sceince and Technology. 47, pp. 92-97 https://doi.org/10.1016/j.ast.2015.09.023

Materials Data Book (2003). Cambridge University Engineering Department. [Online]. Available from: http://www-mdp.eng.cam.ac.uk/web/library/ enginfo/cueddatabooks/materials.pdf [Accessed: 22nd January 2018] 